\title{
ENTRE A DOMINAÇÃO RACIONAL-LEGAL E O CARISMA: o Projeto Tamar e sua intervenção em comunidades pesqueiras do litoral brasileiro
}

\author{
Dulce Maria Filgueira de Almeida Suassuna*
}

\begin{abstract}
Resumo: O trabalho discute a implantação e implementação de políticas públicas para o setor ambiental no Brasil, no período compreendido entre 1970 e 2000 . Nesse contexto, realiza um estudo de caso do Projeto Tartarugas Marinhas (Projeto Tamar), apresentando uma análise comparativa das formas de intervenção em duas comunidades pesqueiras do litoral brasileiro: Praia do Forte (BA) e Regência (ES). Por meio de uma abordagem qualitativa, foram reconstruídos discursos e postos em diálogo para a compreensão. Constatou-se que o Projeto Tamar apresenta formas discursivas que se apóiam no modelo de sustentabilidade causal, isto é, o econômico viabiliza o ambiental. Neste âmbito, verificou-se que a lei e o discurso racional-legal são utilizados como estratégia de dominação em Praia do Forte, enquanto o carisma é parte do tipo ideal de dominação em Regência. Viu-se que essa diferenciação não ocorreu por acaso, mas é fruto de processos de resistência e conflitos que emergiram nas duas comunidades de pescadores e que está relacionada com suas especificidades socioculturais, especificamente quanto à forma como apresentam suas representações sociais e simbólicas sobre a pesca e a caça da tartaruga marinha.
\end{abstract}

Palavras-chave: política pública, meio ambiente, dominação racional-legal, dominação carismática, comunidades pesqueiras.

* Doutora em Sociologia pela Universidade de Brasília, professora da Faculdade de Educação Física da Universidade de Brasília. E-mail: dulce@unb.br

Este trabalho é o resultado da tese de doutorado defendida no Programa de PósGraduação em Sociologia da Universidade de Brasília. Foi apresentado no VIII Congresso Luso-Afro-Brasileiro de Ciências Sociais, em Coimbra, Portugal, em setembro de 2004, com apoio da Capes e da Finatec.

Artigo recebido em 30 ago. 2005; aprovado em 20 out. 2005. 


\section{Introdução}

O trabalho analisa o processo de intervenção do Projeto Tamar (programa de proteção às tartarugas marinhas) em comunidades pesqueiras, buscando-se a construção de um olhar sobre o modo como são definidas as políticas públicas para o meio ambiente no Brasil. Procura-se analisar a dimensão das transformções sociais e o que elas representam em termos de rupturas para as comunidades locais envolvidas e, por conseguinte, possíveis resistências dos indivíduos nativos às mudanças impostas.

O Projeto Tamar é um programa de conservação ambiental, vinculado ao Instituto Brasileiro de Meio Ambiente e Recursos Naturais Renováveis (Ibama), órgão pertencente ao Ministério do Meio Ambiente e Recursos Naturais (MMA). Com a finalidade de auxiliar a intervenção socioambiental, houve a criação, em 1988, de uma organização não-governamental - a Fundação Centro Brasileiro de Proteção e Pesquisa das Tartarugas Marinhas (Fundação PróTamar). A partir de então, o Projeto Tamar se apresenta com uma configuração híbrida (Estado/ONG), pois se relaciona com a ONG de maneira simbiótica.

A intervenção do Projeto Tamar foi iniciada em 1980 e promoveu modificações nos modos de vida das populações envolvidas, alterando não só suas relações sociais, mas também a maneira como se relacionam com o meio ambiente natural. Seu objetivo era a preservação das tartarugas marinhas e, para tanto, esforços foram empreendidos no sentido de alcançá-lo, sem ter-se, todavia, a clareza da dimensão das rupturas ocasionadas.

O Projeto Tamar é parte de uma política pública ambiental configurada em uma intervenção estatal, sendo uma face do Estado aqui entendido como capaz de "exercer funções contraditórias, de acumulação e de legitimidade, para criar as bases de um consenso através da ação das suas instituições" (Jacobi, 1989, p. 4). Assim, a ligação entre o Projeto Tamar e o Estado é de proximidade quando a intervenção necessita da força estatal, podendo, inclusive, apelar-se para o seu poder de fiscalização no exercício da dominação legítima, 
por meio do poder imperativo do Estado com o uso da violência (apreensão de redes de pesca, prisão de pescadores que capturam tartarugas), mas também mantém uma relação de distanciamento quando delega à ONG atribuições que, em tese, deveriam ser suas. Essa relação de proximidade ou de distanciamento constitui uma ambigüidade do Projeto Tamar, podendo suscitar um conflito de identidade para os próprios sujeitos que o constituem e para os indivíduos das comunidades.

Para a compreensão da intervenção do Projeto Tamar nas comunidades pesqueiras, duas observações são cabíveis: 1) os sujeitos que constituem o Projeto Tamar são os mesmos que integram a Fundação Pró-Tamar, havendo confusão de seus papéis sociais; 2) a intervenção se dá de modo continuado, portanto, é vista como um processo, que teve início com a fixação de bases de proteção durante a década de 80, e segue até os dias atuais.

A pesquisa, com abordagem qualitativa, foi realizada entre 1997 e 2001, quando foram entrevistados 63 indivíduos (das comunidades pesqueiras e do Projeto Tamar) e o trabalho de campo foi realizado em duas vilas de pescadores (Praia do Forte e Regência), além de Brasília/DF, onde foi entrevistada uma das fundadoras do Projeto Tamar. A análise do material coletado seguiu a orientação teóricometodológica da sociologia weberiana. Para tanto, buscou-se a interpretação do sentido atribuído pelos diferentes atores sociais, que são partes do processo de intervenção: Estado, ONG e indivíduos das comunidades intervindas.

Praia do Forte é uma vila de pescadores, localizada no litoral norte do Estado da Bahia e pertence ao município de Mata de São João, área de influência da Região Metropolitana de Salvador (RMS) e do município de Camaçari (pólo petroquímico). Sua população é de 1.126 habitantes, sendo 534 homens e 592 mulheres (Fundação Garcia D’Ávila, 1998). Nessa localidade, 400 homens utilizam um sistema de pesca artesanal; destes, 70 são pescadores de alto mar e 330 são chamados de "marisqueiros".

Em Praia do Forte estão localizadas as sedes nacionais do Projeto Tamar e da Fundação Pró-Tamar. Foi a terceira das três 
comunidades que sofreram o processo de intervenção do Projeto Tamar, sendo a que tem maior visibilidade nacional e internacional. Tornou-se um refúgio particular da vida silvestre, onde são asseguradas condições para a existência ou reprodução de espécies ou comunidades da flora local e da fauna residente ou migratória, sendo da categoria unidade de conservação de proteção integral (Lei 9.985/2000, art. 13, caput). A unidade de conservação (UC) ficou definida por 1.384 quilômetros quadrados (Funatura, 1987; Marcovaldi et al., 2000).

O poder do Projeto Tamar no local aparece de modo diluído, em função das terras que compreendem a UC serem propriedade particular. Entretanto, por ser um programa do governo federal, o Projeto Tamar tem legitimidade diante daquela comunidade, especialmente perante os pescadores, tendo em vista que tem competência para fiscalizar a atividade pesqueira no local, fazendo uso do "poder de polícia". Pode-se afirmar que no local há a concepção de "natureza mercantil", posto que tanto os proprietários da área quanto o Projeto Tamar desenvolvem programas relacionados ao ecoturismo.

Além de Praia do Forte, a pesquisa também foi realizada em Regência, outra vila de pescadores, pertencente ao município de Linhares, localizada no litoral norte do Estado do Espírito Santo. A população de Regência pode ser dividida entre os que habitam a zona rural - 4.002 pessoas $(72,18 \%)$ - e zona urbana - 1.542 pessoas $(27,82 \%)$, totalizando 5.544 habitantes, e a distribuição por sexo dos moradores da zona urbana é a seguinte: 801 homens e 741 mulheres (IBGE-Linhares/ES, 1999). Apesar de haver um grande número de pessoas habitando na zona rural, o elemento humano considerado na pesquisa está localizado na zona urbana, precisamente o centro da vila de pescadores de Regência. Esse recorte se dá em função da intervenção do Projeto Tamar no local, posto que suas políticas buscam alternativas de sustentabilidade apenas para os pescadores da região e suas famílias, por serem eles os predadores das tartarugas marinhas. Em Regência, 60 pescadores estão inscritos na Colônia de Pesca de Linhares (ES). A Associação de Pescadores de Regência, criada 
pelo Projeto Tamar por volta de 1998, tem 20 associados e 9 diretores. O sistema de pesca dos nativos é artesanal e simbólico, se orientando pelo segredo. Os pescadores de Regência realizam a pesca no rio, indo ao mar apenas quando há condições propícias.

Regência pertence à coordenação do Projeto Tamar da Região Sudeste e tem algumas singularidades que lhe dão grande relevância para este estudo. A primeira é sua característica geofísica: local de difícil acesso, com mar de águas perigosas, entrecortado pelo Rio Doce, situada dentro de uma reserva biológica, da categoria de unidade de conservação de proteção integral (Decreto $\mathrm{n}^{\circ}$ 90.222, de 25 de setembro de 1984), tendo 833 hectares, sendo $100 \%$ das terras da reserva pertencentes à União. Ao contrário de Praia do Forte (cuja coordenação é a da Região Nordeste), a base de Comboios, situada em Regência, não é aberta à visitação, havendo um controle incisivo do Projeto Tamar sobre o crescimento urbano no lugar, identificandose a intenção de transformá-la em natureza doméstica. Diante do exposto, constata-se que a intervenção do Projeto Tamar apresenta dois modelos de intervenção: um, que se sustenta na idéia de natureza mercantil e, outro, que foi construído com base na noção de natureza doméstica.

\section{Transformação social: categoria central de análise}

As rupturas promovidas durante a intervenção do Projeto Tamar nas comunidades pesqueiras se apresentam em duas direções: transformar Praia do Forte em uma natureza mercantil e fazer com que Regência permaneça uma vila de natureza doméstica. Esses dois modelos, que funcionam como espécies de tipos ideais, foram adotados para este trabalho a partir da construção de Godard (1997) e servem para delinear as vilas de pescadores, pois possibilitam a construção de uma caricatura, que certamente não se apresenta de modo engessado, reconhecendo-se a diferença entre real e ideal.

Todavia, analisando-se as duas comunidades a partir dos modelos construídos, pode-se perceber claramente a ocorrência de 
mudanças significativas nos modos de vida dos indivíduos nativos, tais mudanças são consideradas como transformações sociais por promoverem rupturas reais e simbólicas nos sujeitos intervindos. Oportuno salientar, portanto, que, por vezes, o processo de intervenção produz uma verdadeira "catástrofe da comunidade nativa [que] é o resultado direto da ruptura rápida e violenta das instituições básicas da vítima (não parece relevante se a força é usada ou não no processo)" (Polanyi, 2000, p. 193).

Considera-se Praia do Forte como uma vila de natureza mercantil, por sua condição peculiar, pois trata-se de uma propriedade particular que apresenta uma infra-estrutura turística, fazendo parte do roteiro ecoturístico do Brasil. Existe uma proporcionalidade em relação à sustentabilidade ambiental e econômica na vila, posto que, ambientalmente, foram definidos esforços para se fazer cumprir todos os procedimentos jurídicos e, economicamente, foram viabilizados projetos dirigidos ao ecoturismo para possibilitar a adequada exploração da natureza. Todavia, do ponto de vista social, alguns aspectos merecem melhor apreciação.

Em Praia do Forte, os pesquisadores do Projeto Tamar e os proprietários apresentam interesses convergentes, sendo este aspecto objeto de crítica pela comunidade local. Neste âmbito, os indivíduos nativos sentem-se excluídos da participação nas decisões que emanam do poder, pois, para eles, o Projeto Tamar, enquanto representante do Estado, deveria defender os interesses da coletividade e não os de particulares. Constata-se, com essa situação, que há a identificação do modelo capitalista por parte do Projeto Tamar, resultando em situações de conflito à medida que o Projeto fiscaliza tanto a captura da tartaruga marinha, quanto a pesca na região.

A perspectiva dos proprietários da área foi dirigida à exploração econômica, tomando a natureza como mercadoria, isto é, procuraram meios para que fossem retirados da natureza, com base na apropriação e troca, valores que se transformam em bens e serviços, como por exemplo, a exploração turística das paisagens da praia. Por meio da 
idéia de natureza mercantil, ela torna-se um elemento de apropriação e troca, isto é, uma mercadoria (Godard, 1997), mas, enquanto tal, a natureza está dissociada do estado natural (idéia de original, apresentada por Merleau-Ponty, 2000), situando-se no contexto da produção. Essa perspectiva tomada pelo autor vai ao encontro do conceito de natureza em Husserl (citado por Merleau-Ponty, 2000), cuja compreensão é a de que a natureza é produto da percepção humana.

Em Praia do Forte, a natureza torna-se objeto de apropriação e troca por meio de sua beleza paisagística, correspondendo à associação entre a oferta de bens e serviços (como, por exemplo, o ecoturismo) e as representações da natureza. Interessante observar que, inclusive, o fato de ser "vila de pescadores" faz parte da construção escênica do lugar, funcionando como um atrativo turístico. Assim, a instalação do Projeto Tamar na área significou a legitimação dos interesses privados impostos aos indivíduos da comunidade, que até então, tinham a apropriação da natureza.

A forma como o processo de intervenção do Projeto Tamar ocorreu em Praia do Forte suscitou questionamentos dos moradores nativos - pescadores. Se entre proprietários e Projeto Tamar houve a construção de uma relação calcada em mecanismos de encaixe e na confiança nos sistemas peritos (Giddens, 1991), a perspectiva dos que sofreram a intervenção foi outra.

Durante o trabalho de campo verificou-se que a comunidade desejava expressar seus anseios, "ser ouvida", não só como forma de resistência ao processo de intervenção da política - Projeto Tamar-, mas também para confrontar-se aos proprietários, que, assim como os agentes do Projeto Tamar, eram indivíduos de fora da comunidade. Nas entrevistas, muitos pescadores mostravam-se críticos à atuação conjunta daqueles dois atores sociais, e percebiamna como forma de justificar ações autoritárias, não só para controlar a urbanização e o crescimento do lugar, mas, também, para defender interesses particulares, que se mostravam contrários aos da comunidade. Verifica-se, portanto, a constituição de uma situação de 
confronto à política intervencionista, que é identificada como uma confusão de papéis sociais.

Nesse âmbito, o Projeto Tamar funciona como instrumento de poder nas mãos de interesses particulares (proprietários da área) e é compreendido na racionalidade dos pescadores como desencadeador da dominação racional-legal, cuja atribuição é fiscalizar e punir os pescadores. Eles enxergam os interesses dos proprietários e do Projeto Tamar como sendo único. Dentro de sua complexidade, o cenário se transforma em "locus de uma dinâmica de harmonização e integração, que acaba corporificando espaços de confrontação de lógicas setoriais, cujo desafio equivale à dominação de um deles sobre os outros. Nessa confrontação, o jogo de cada órgão consiste, de certa forma, em se tomar a parte pelo todo" (Godard, 1997, p. 226).

Apropriando-me da idéia do autor, pude compreender a dimensão do conflito instaurado em Praia do Forte. A confrontação entre as duas lógicas setoriais é assumida como uma relação simbiótica entre interesses particulares e governamentais, de um lado, e pescadores e suas famílias (comunidade), do outro. Estabeleceu-se, assim, um paradoxo entre os atores de fora - estranhos à comunidade - e os atores 'de dentro' - indivíduos que a integram. O paradoxo entre os dois pólos da luta travada entre os atores sociais pode ser interpretado como um afrontamento. Inicialmente esse afrontamento deflagra uma relação de oposição, porém, posteriormente, engendra formas derivadas. As formas derivadas podem surgir a qualquer momento, desde que haja um contexto apropriado para o estabelecimento do conflito.

Caso se perceba o meio ambiente e a natureza como objetos cotidianos de uma disputa travada por atores sociais em relação à maneira de qualificá-los, pode-se compreender porque a busca de legitimação é um elemento tão importante do processo, tendo em vista que pode servir para ordenar ou classificar os indivíduos em grupos, definindo as relações de poder, por meio de forças em oposição. No caso em tela, a lei é vista como um recurso aliado ao poder dominante (tanto pelo direito de propriedade, quanto pela 
fiscalização e punições). Por isso, "os dominados" engendram caminhos diferenciados para estabelecer seu afrontamento com vista a assegurar sua legitimidade.

Os pescadores expõem em suas falas que a atuação do Projeto Tamar deve ser ampliada, discordando de sua restrição à proteção das tartarugas marinhas. Essa demanda existe porque o Projeto Tamar está inserido nas comunidades, daí lhe cobrarem maior participação. Questionam o fato das contratações serem privilégio de alguns antigos pescadores ou seus parentes, situação que é vista como modo de exclusão social.

De qualquer forma, estava posto o conflito de interesses ou o afrontamento entre esferas heterogêneas a partir das relações de poder e dos mecanismos de controle social: Projeto Tamar versus proprietários e os indivíduos nativos.

Outro elemento que contribuiu para acender as chamas do conflito é o modelo de sustentabilidade e a sua implementação. Por tratar-se de um projeto de "natureza mercantil", em Praia do Forte a sustentabilidade ambiental e econômica apareciam como centrais, desconsiderando-se a sustentabilidade social e cultural. Registra-se que qualquer projeto que vislumbre o desenvolvimento sustentável deve ser construído com base nas cinco dimensões de sustentabilidade: social, econômica, ecológica - ambiental -, espacial e cultural (Sachs, 1993).

O modelo adotado em Praia do Forte resultou na imposição de uma força exterior às consciências coletivas (da comunidade), que modificou práticas sociais e culturais ou folks. Os pescadores identificam o proprietário da área e os pesquisadores do Projeto Tamar como de fora e defendendo interesses diferentes daqueles da comunidade, enquanto impõem novas práticas sociais, vindas a partir da preservação das tartarugas marinhas.

Em Praia do Forte, o hábito de caçar a tartaruga era aliado às práticas pesqueiras. Os pescadores de Praia do Forte coletavam os ovos de tartarugas e as capturavam para se alimentarem, algumas 
vezes porque "o peixe não dava", outras vezes porque tinham o costume de praticarem a caça. Além disso, pelas condições propícias do local para a desova da tartaruga de pente, alguns indivíduos da comunidade usavam o casco desse animal para produzir objetos como pentes, anéis, pulseiras, que eram comercializados, de modo a complementar a renda familiar que vinha da pesca.

A associação entre a caça da tartaruga e a pesca não é casual. Ocorre porque, como contam os pescadores, quando iam à praia, à noite, para pescar, eles encontravam tartarugas pelo caminho, seguiam seu rastro e facilmente localizavam os ovos, que eram retirados. Às vezes, matavam a tartaruga e levavam a carne para casa, outras vezes só observavam-na, deixando-a voltar ao mar.

Entende-se que o enraizamento da caça e do hábito alimentar das tartarugas permite a interpretação das falas - o "dito" - num jogo de linguagem em que expressa sua eficácia simbólica, demonstrada por meio de sinais capazes de produzir "coisas sociais". Com isso se sugere a existência da validação do dito, a partir de sua interpretação, seguindo a orientação de Hirsch (1967). Assim, embora um pescador contratado pelo Projeto Tamar afirme que as tartarugas não faziam parte de suas práticas, outros admitem que elas serviam para alimentação.

As tartarugas estão inseridas nos hábitos e práticas cotidianas por serem parte de uma disputa (um jogo) entre os pescadores, para se identificar quais eram os mais experientes na captura. Essa identificação funciona como um mecanismo de reconhecimento social dentro da comunidade. Assim, as tartarugas marinhas apresentavam um valor simbólico para os nativos, construindo-se a partir da captura um sistema de classificação para demonstrar quem eram os melhores na região. A captura das tartarugas era um fato que ocorria com regularidade e que estava enraizado na consciência coletiva dos moradores nativos, tendo eficácia simbólica, ou seja, havia a incorporação da noção de habitus, que compreende a regularidade de condutas como um sistema de disposição para a prática (Bourdieu, 1990). Nesses termos, sugere-se que a chegada do Projeto Tamar 
na comunidade representou modificações nos hábitos e comportamentos culturais dos pescadores, incorrendo no perigo de deslocar o reconhecimento de suas identidades por legitimar a identidade dominante.

A dimensão das rupturas causados no horizonte do nativo pode ser interpretada a partir da aceitação ou não do novo. De um lado, estão aqueles que constroem a crítica por meio do afrontamento; de outro, estão os que aceitam os valores que passam a ser impostos por meio do processo de intervenção do Projeto Tamar em Praia do Forte. São, em sua maior parte, indivíduos que têm algum vínculo econômico: pescadores que se tornaram tartarugueiros; pais cujos filhos trabalham no Projeto Tamar; lideranças que recebem verba por meio de convênios com o Projeto Tamar. A consciência desses indivíduos foi sendo paulatinamente integrada para dar ensejo à formação de uma outra consciência coletiva, cujo sentido de preservação das tartarugas pretende-se que tenha sido incorporado. Nesse contexto, pode-se perceber o surgimento de um novo grupo social formado pelos indivíduos que são da comunidade, mas que, durante o processo de intervenção, assumem como seus os valores determinados pelos atores de fora (sujeitos do) Projeto Tamar.

Para reforçar o processo de desconstrução da identidade do nativo, os pesquisadores do Projeto Tamar afirmam que as tartarugas não eram apreciadas como fonte de alimentação pela população de Praia do Forte (apesar de ser uma das áreas em que aqueles animais estavam mais ameaçados pela extinção, posto que a tartaruga de pente desova prioritariamente naquela praia). Sugerem, na construção de seus discursos, que as tartarugas não faziam parte da cultura local. Porém, ao mesmo tempo, reconhecem que, ao chegarem à Praia do Forte, em 1980, identificaram em algumas casas de moradores cascos de tartarugas servindo como adornos.

As informações coincidentes de que havia um número significativo de desovas e que muitos animais eram capturados em redes de pesca, ou mesmo quando vinham à praia para a reprodução, propiciaram o desenvolvimento de um trabalho incisivo junto aos 
indivíduos da vila de pescadores de Praia do Forte. Além disso, induziram que apesar de os ovos serem retirados quando da desova das tartarugas na praia, eles não eram apreciados pelos indivíduos da comunidade local e que a tartaruga não apresentava a mesma importância "cultural” comparando-se, por exemplo, com Regência.

Por outro lado, verifica-se que o Projeto Tamar sofreu algumas resistências em sua implantação, a ponto de uma das moradoras que apoiava o trabalho de preservação das tartarugas duvidar que o projeto conseguiria êxito. A dúvida não se dava em relação à implantação da política pública na área, mas na forma como seria implementada em função da continuidade dos hábitos da população local. Essa continuidade - que assegurou a eficácia simbólica das tartarugas marinhas no habitus da comunidade - pode ser interpretada como uma resistência ao novo, a um processo de preservação da cultura e que não se sujeitava, naquele momento, a uma "aculturação". A resistência é aqui entendida como uma reprovação do sentido de apropriação da natureza, que era referência do cotidiano dos indivíduos da comunidade, representando a não-aceitação de um fato exterior que se impõe às maneiras de agir não-fixas, consubstanciadas em práticas institucionalizadas na consciência coletiva da comunidade (como a caça às tartarugas).

Em Regência, pode-se afirmar que o Projeto Tamar tem a pretensão que a vila permaneça com características de uma "natureza doméstica", ou seja, pretende mantê-la com seus aspectos tradicionais, buscando o reforço à consciência coletiva do grupo, incentivando práticas culturais que fazem parte do sistema ritual dos moradores nativos. A intervenção do Projeto Tamar ocorreu a partir de 1982, quando se deparou com uma realidade singular: a tartaruga era chamada de careba, lembrança dos antepassados tupiniquins (Marcovaldi et al., 2000). A presença dos pesquisadores na região foi confundida com o poder de repressão da Sudepe, na época responsável pela fiscalização da pesca, criando-se dificuldades para os pesquisadores na vila. 
Nessa vila de pescadores, a identidade dos indivíduos era estabelecida a partir da caça de tartarugas e da pesca. Essa constatação parte do próprio Projeto Tamar ao afirmar que a careba (denominação atribuída à tartaruga marinha na região) era uma espécie de arte que os pescadores utilizavam e que estava incorporada nos seus modos de vida e, para mim, no seu sistema de representação coletiva. Todavia, os pescadores de Regência preferem falar da pesca hoje, mostrando-a como atividade produtiva. Mas, realçam em suas falas (pelo menos $80 \%$ deles) os conflitos que surgem na comunidade a partir da presença de pescadores de fora. Para os nativos, a pesca é o meio de subsistência e uma das formas de se apropriar da natureza, visto que a caça da careba é proibida. Ao falarem da pesca hoje, eles estão mostrando que ela mudou por causa dos pescadores de fora. Desta forma, pode-se estabelecer uma relação entre as mudanças da pesca depois da chegada dos pescadores de fora, e da careba depois da intervenção do Projeto Tamar na comunidade. Será que ao falarem da pesca hoje eles pretendem ser atores sociais (construtores de suas histórias, cf. Arendt, 2000), tendo capacidade para agir antes que a mudança penetre em todo o sistema de representações coletivas? Uma das falas de um pescador nativo pode ajudar a responder essa questão; ele diz: "eles pensam diferente da gente aqui”, reportando-se aos pescadores de fora.

Assim, a pesca, antes da chegada dos pescadores de fora (por volta de 1996), e a caça das tartarugas, antes da entrada do Projeto Tamar (em 1982), eram formas de apropriação da natureza para a comunidade de Regência. Eram os dois meios que eles tinham para definir o trabalho, que aparece para eles como um elemento muito importante. Isto é, o trabalho, especialmente o pesqueiro, é um aspecto fundamental de construção identitária da população nativa. Tal constatação pode ser percebida a partir da construção "mítica" da região: o Caboclo Bernardo, um mito heróico a partir de seu esteriótipo de homem trabalhador. Disse uma das entrevistadas: "o Caboclo Bernardo era um sujeito muito trabalhador, tão trabalhador que morreu trabalhando". Aqui se pode afirmar que as tartarugas marinhas saem do cenário porque os indivíduos da comunidade 
pretendem preservar o que ainda resta de suas percepções sobre a natureza: a pesca, pois a ruptura com a caça da careba já ocorreu de forma material. Assim, as relações sociais e o sistema de representações dos indivíduos buscam na pesca a apropriação da natureza.

Os pescadores temiam que o grupo do Projeto Tamar pudesse apreender redes e demais artefatos e por essa razão utilizaram-se de um recurso sutil, mas com um efeito impactante. Falavam das tartarugas por meio de relatos, contando histórias, que, apesar de serem reportadas aos antepassados, de fato se passavam com eles. Eram formas de falar e, ao mesmo tempo, omitir os fatos que eram parte de sua consciência coletiva. Na verdade eles estavam resistindo ao contato com uma cultura diferente da sua, e, ao falarem sobre o passado, deixando o presente em suspense, pode ser interpretado a partir do sentido de retrospecção, termo usado por Bourdieu (1989), a partir de Husserl (1977). Segundo os autores, a retrospecção é uma forma inteligente de dar sentido às suas práticas no presente, porém deixando sempre "em aberto" suas formulações sobre ele.

A tartaruga marinha, à semelhança do que ocorre em Praia do Forte, representava para a população de Regência uma fonte de alimentação. Além disso, era parte da tradição local - carebar -, ou seja, capturar à noite tartarugas que vinham à praia para desovar. Conforme pude perceber, embora a careba fosse uma prática pertencente ao universo masculino do pescador outros indivíduos na comunidade também participavam.

Na identificação do horizonte semântico do nativo percebe-se facilmente a idéia de retrospecção, em que o indivíduo se coloca na história como narrador. Por trás da idéia de voltar ao passado existe um fator muito importante: o sentido de natureza que era partilhado pelos indivíduos nativos. É como se os que chegam (Projeto Tamar) começassem a se apropriar da natureza que pertencia aos que lá estavam. Mais uma vez me reporto à noção de contato cultural com base em Polanyi (2000, p. 55) para entender o processo de intervenção e suas implicações em Regência: “O ritmo da mudança não é menos 
importante do que a direção da própria mudança; mas enquanto essa última freqüentemente não depende da nossa vontade, é justamente o ritmo no qual permitimos que a mudança ocorra que pode depender de nós". Tratando das transformações ou mudanças que ocorreram no século XIX, o autor procura entender a ineficácia das leis, durante aquele período, como parte de uma circunstância em que é necessário recuar para se conseguir alterar o ritmo da mudança.

No processo de intervenção do Projeto Tamar os indivíduos da comunidade compreenderam que seria difícil (talvez impossível) interromper por completo as mudanças que a política ambiental determinava. Conquanto construíram relatos retrospectivos para "frear" o ritmo da mudança e, com isso, possibilitaram que a apropriação do sentido de natureza que eles preservavam por meio de suas práticas (careba e, como se verá adiante, a pesca) permanecesse por mais tempo na consciência coletiva da comunidade. Se esses indivíduos da comunidade continuam contando a história da caça das tartarugas por meio de relatos retrospectivos, pode significar que, em sua consciência coletiva, a prática da careba ainda seja parte de suas vidas (pelo menos no sistema de representações coletivas).

\section{Conclusão}

As políticas modernas de Estado modificam cenários, produzindo quadros patológicos, sem se preocuparem com suas consequiências. Um quadro anômico pode ser interpretado no caso de Praia do Forte e ser estendido à de Regência por meio de duas diretrizes. A primeira está relacionada ao significado do componente estrutural-cultural (cultura nativa). Nela, verificou-se que houve perda de referência dos indivíduos (pescadores), com a perturbação de suas identidades coletivas e ruptura com suas tradições, sendo talvez este o elemento mais marcante, pois os pescadores e tartarugueiros ou carebeiros construíam seus mitos, suas representações coletivas institucionalizadas socialmente, com base na pesca e na caça das 
tartarugas marinhas. A outra diretriz está determinada pelo componente estrutural - a sociedade. Nela, as mudanças se processaram por meio da perda de referência em relação à legitimidade de suas práticas (pesca e careba) e com a instauração de uma anomia social, dado que foram agregadas novas relações sociais, como por exemplo, referentes ao significado de natureza e ao sentido de carebar. A contratação de alguns pescadores promoveu uma "fragilização" da consciência coletiva, significando a retirada da motivação desses atores sociais. Nessa compreensão, qualquer processo de intervenção que implique a justaposição de um modelo de dominação sobre outros é um modelo que produz conflitos ou situações de crise.

Por fim, concluo que a complexidade das relações se verifica de duas formas:

1) por meio da configuração híbrida adotada pelo Projeto Tamar durante o processo de intervenção, que relaciona, numa rede, o Estado - representado pelo Ibama - e um organismo não-governamental - correspondente à Fundação PróTamar. Essa configuração assegura legitimidade às relações de poder e dominação do Projeto Tamar durante o processo de intervenção, veiculando suas estratégias discursivas, dirigidas à preservação da natureza, a partir das tartarugas marinhas;

2) o Projeto Tamar utiliza tipos diferenciados de discursos que podem variar de acordo com a relação que mantém com a comunidade, e que, nos momentos caracterizados como "situações de crise", pode haver permeabilidade entre o discurso de dominação racional-legal e o carismático, e viceversa, desde que lhe seja assegurada a manutenção do poder.

Do ponto de vista da construção das estratégias discursivas dos indivíduos das comunidades de pescadores tem-se a definição de dois discursos. O primeiro é estabelecido por meio do embate direto ou afrontamento, em que são claras as formas de resistência 
ao poder de dominação racional-legal do Projeto Tamar. O outro é estabelecido com base no uso de estratégias quase invisíveis, em que os indivíduos mostram-se resistentes sem construir um discurso combativo, mas buscando a retrospecção ou agindo de acordo com suas tradições, não aceitando, portanto, sua ruptura. Todas essas ações são dotadas de racionalidade, carregando consigo um sentido subjetivamente visado.

O Projeto Tamar, por seu turno, não admite no seu discurso oficial qualquer forma de resistência das comunidades envolvidas. Essa inadimissibilidade é devida à necessidade de buscar legitimidade para sua intervenção enquanto programa de conservação ambiental de natureza governamental, por isso dilui as resistências no seu discurso dominador. Entretanto, a pesquisa revelou que, por mais que o Projeto Tamar formule estratégias discursivas para a construção do processo de intervenção, os indivíduos das comunidades conseguem ter a dimensão dessas estratégias e constroem discursos de resistência (ou direta, ou simbólica).

A pretensão do Projeto Tamar em veicular seu discurso ofuscando as resistências a partir do sentido de "formação da consciência ambiental" foi constatada e é parte do jogo político que o programa estabelece nas comunidades. Esse jogo político pode ser compreendido como a luta pela hegemonia em relação ao poder e à dominação do Projeto nas comunidades.

Em relação ao Projeto Tamar posso afirmar, finalmente, que o discurso veiculado sobre a "formação da consciência ambiental" tem um limite que é definido pela sua necessidade (econômica). O que sugere que, diante do processo de intervenção, as relações de poder e dominação não formaram uma "consciência ambiental" nos indivíduos das comunidades envolvidas, sendo esta "pseudoconsciência" circunstancial. Assim, se o Projeto Tamar (Estado/ONG) deixar de manter relações de poder e dominação, por meio do controle social, as tartarugas continuarão sendo mortas indiscriminadamente. 
Abstract: Between rational-legal domination and carisma: the Tamar Project and its intervention in fishing communities at the Brazilian coast

The present work discusses the implantation and implementation of political policies for the environmental sector in Brazil during the period between 1970 and 2000. In that context, it performs a study of case of the Sea Turtle Project (Tamar Project), presenting a comparative analysis of the forms of intervention in two fishing communities at the Brazilian cost: Praia do Forte (in the State of Bahia) and Regência (in the State of Espírito Santo). Discourses were reconstructed and put into discussion in order to be comprehended, through a qualitative approach. It was verified that the Tamar Project presents discursive forms which lean on the causal sustainability model, which is the economic side makes the environmental side viable. Within that framework, it could be verified that the law and legal-rational discourse are being used as a strategy of domination in Praia do Forte, while the charisma is part of the ideal type of domination in Regência. It was also noticed that this difference does not occur by accident, but it is a consequence of the process of resistance and conflicts which emerged in both fishing communities and is related to their social-cultural specificities, specifically in the way they show their social and symbolic representations about the fishing and hunting of sea turtles.

Key-words: public policies, environment, legal-rational domination, charisma, fishing communities.

\section{Referências bibliográficas}

ARENDT, H. A condição humana. 10. ed. Rio de Janeiro: Forense Universitária, 2000.

BOURDIEU, P. Coisas ditas. São Paulo: Brasiliense, 1990. . O poder simbólico. Lisboa: Difel, 1989.

BRASIL. Lei 9.985, de 18 de julho de 2000. Regulamenta o art. 225, $\S 1^{\circ}$, inciso I, II, III e VII da Constituição Federal, institui o Sistema Nacional de Unidades de Conservação da Natureza e dá outras prividências. Disponível em: 〈http://www.planalto.gov.br/ccivil_03/leis/19985.htm〉.

FUNATURA. Plano de Manejo de Praia do Forte. Brasília, 1987. 
FUNDAÇÃO GARCIA D’ÁVILA. Registros etnográficos. 1998.

GIDDENS, A. As conseqüências da modernidade. São Paulo: Ed. UNESP, 1991.

GODARD, O. A gestão integrada dos recursos naturais e do meio ambiente: conceitos, instituições e desafios de legitimação. In VIEIRA, P. F.; WEBER, J. (Orgs.). Gestão de recursos naturais renováveis e desenvolvimento: novos desafios para a pesquisa ambiental. São Paulo: Cortez, 1997.

HIRSCH Jr., E. D. Validity in Interpretation. Michigan: Yale University Press, 1967.

HUSSERL, E. Cartesian Meditations. The Hague: Martinus Nijhoff, 1977.

IBGE-Linhares/ES. Registros etnográficos. 1997.

JACOBI, P. Movimentos sociais e políticas públicas. São Paulo: Cortez, 1989.

MARCOVALDI, M. A. et al. Marine turtles of Brazil: the history and structure of Projeto Tamar-Ibama. Biological conservation, v. 94, n. 1, p. 43$50,1999$.

Assim nasceu o Projeto Tamar. Salvador: Fundação Pró-Tamar, 2000.

MERLEAU-PONTY, M. A Natureza: notas de cursos no Collège de France. Texto estabelecido e anotado por Dominique Séglard. Tradução de Álvaro Cabral. São Paulo: Martins Fontes, 2000.

POLANYI, K. A grande transformação: as origens de nossa época. 2. ed. Rio de Janeiro: Campus, 2000.

SACHS, I. Estratégias de transição para o século XXI. In: BURSZTYN, M. Para pensar o desenvolvimento sustentável. São Paulo: Brasiliense, 1993.

. Caminhos para o desenvolvimento sustentável. Rio de Janeiro: Garamond, 2000.

WEBER, M. Sociologia. São Paulo: Ática, 1986. (Coleção Grandes Cientistas Sociais). 